\title{
XLII. Carbon dioxide as a constituent of the atmosphere
}

\author{
Ernest H. Cook B.Sc. A.R.C.S.
}

To cite this article: Ernest H. Cook B.Sc. A.R.C.S. (1882) XLII. Carbon dioxide as a constituent of the atmosphere, Philosophical Magazine Series 5, 14:89, 387-395, DOI: $10.1080 / 14786448208627280$

To link to this article: http://dx.doi.org/10.1080/14786448208627280

曲 Published online: 28 Apr 2009.

Submit your article to this journal $₫$

Џ Article views: 2

Q View related articles $₫$ 
depends on the properties of the layer forming the component of the pair nearest to the kathode ; or, shortly, each layer, or the conditions existing at its point of origin, always influence the layer following next to it, on the side of the anode, but does not influence the preceding, on the side of the kathode. The conditions under which the $n$th layer forms seem to stand to the properties of the $n+1$ th layer in the relation of cause and effect; and hence it seems to me only a verbally different expression of the observed facts if we assume, as above, that the propagation of the electrical tensions, or the production of the separate layers, takes place in the direction of increasing values of $n, i$. e. advances from the kathode towards the anode.

Berlin, Physical Institute of the University.

XLII. Carbon Dioxide as a Constituent of the Atmosphere. By Finnest H. Cook, B.Se. (Lond.), A.R.C.S., Lecturer upon Chemistry and Physics at the Bristol Mining School*.

() $\mathrm{F}$ all the agents which have brought about geologic changes and mudified the surface of the earth from time to time, the atmosphere seems to have been the least studied. Nor is this very surprising when we remember the peculiarity of its action. So general and cosmopolitan are its effects that their very abundance causes us to overlook them-and, again, so slowly acting that the changes effected require the employment of long periods of time. The two constituents of the atmosphere which have been most active in producing these changes are the oxygen and the carbon dioxide. The latter substance occurs in the air in such a relatively small amount that we are apt to underrate its influence. But when it is remembered that, were it not for the presence of this substance in the air, no coal and very little limestone could have been formed, we at once see its importance. In fact, to come somewhat nearer home, without carbon dioxide in air no vegetable growth could take place; and without plant life very little, if any, animal life would occur. Thus this substance, although in itself inimical to most forms of animal life, is absolutely necessary in the atmosphere in order that those animals may exist. In the present paper an attempt is made to consider some of the results arising from the presence of this substance.

* Read before the American Association for the Advancement of Science at Montreal, on August 25, 1882. Communicated by the Author. 


\section{Amount of Carbon Dioxide in the Atmosphere.}

This question has been made the subject of experiment by many of our leading chemists. In order to calculate the absolute amount, we require to know two things-viz. the capacity or weight of the air, and the percentage of $\mathrm{CO}_{2}$ which it contains. Fortunately the data for doing this have been determined with very great accuracy. The lengths of the diameters of the earth have been determined to be very nearly 7899 miles for the polar and $7925 \frac{1}{2}$ for the equatorial ; " and in these measures it is pretty certain that there is not an error of a quarter of a mile" *. Applying the ordinary rule for the cubic content of an oblate spheroid, we obtain $259,026,554,299$ cubic miles as the capacity of the earth. Now the height of the homogeneous atmosphere is found to be 26,214 feet + , or very nearly 5 miles; calculating the capacity of the spheroid formed by adding this distance to the lengths of the diameters given above and subtracting the capacity of the earth, we obtain the cubic content of the atmosphere supposed homogeneous: this is found to be 591,647,337 cubic miles. With regard to the amount of carbon dioxide present in the air, the older experimenters, Dumas and Boussingault (Ann. Ch. Phys. iii. pp. 257, 288), Löwy and Saussure (Pogg. Ann. xix. p. 391), have published results which yield a mean of 4 vols. in 10,000 of air, or $4 \frac{1}{2}$ parts in 10,000 by weight. Thorpe (Journ. Chem. Soc. vol. xx. p. 189) has shown that over the sea the average is 3 vols. in 10,000; while Saussure states that at high altitudes the proportion of dioxide is greater than at lower levels. Without deviating very far from the truth we may take 4 vols. in 10,000 of air; and we thus find (assuming capacity of air to be $592,000,000$ cubic miles) 236,800 cubic miles as the amount of $\mathrm{CO}_{2}$ in the atmosphere. Finally, calculating from the specific gravity, we find the weight to be 4287 billions of pounds. Expressed on the metric system these figures become:-

Cubic capacity of air... 2,439,987,200,000,000,000 kilolitres. Weight of $\mathrm{CO}_{2}$ in air... 1,913,685,908,480,000 kilogrammes.

I have given these calculations somewhat in detail because of the great difference between my numbers and those hitherto published. Thus, Dumas and Boussingault (op. cit.) say that the air is equal in weight to 581,000 cubes of copper each having a side of 1 kilometre: this gives 4,200,000,000,000,000,000 kilolitres as the capacity of the air, or very nearly 40 per cent.

* Herschell, 'Familiar Lectures,' p. 53.

+ Maxwell, 'Theory of Heat,' p. 228. 
too high. Again, Roscoe and Schorlemmer ('Chemistry,' vol. i. p. 449) state that "the amount of $\mathrm{CO}_{2}$ in the atmosphere reaches to upwards of 3000 billions of kilogrammes," which is about 33 per cent. in excess of the truth*.

\section{Sources whence the Air derives its Carbon Dioxide.}

These are mostly natural ; but the progress of civilization has added a large artificial supply to those already existing. We may state them as follows:-

(1) Combustion of carbonaceous bodies.

(2) Respiration of animals.

(3) Decomposition of vegetable and animal substances.

(4) Volcanos and other subterranean supplies.

Under the first heading is included the amount produced by the burning of coal, wood, peat, \&c. From the most recently issued statistics with regard to the amount of coal raised in the world that I have been able to consult $\dagger$, I find that for the last three years at least 280 millions of tons have been raised annually. This is probably a slight underestimate. Assuming that 75 per cent. of this consists of pure carbon, which if completely burnt in air would produce $\mathrm{CO}_{2}$, and allowing a further 10 per cent. for the carbon thrown away with the ash, we leave 182 millions of tons which are annually converted into carbon dioxide. This will produce $1,800,000$ tons per day, or very nearly 1800 millions of kilogrammes per day. Assuming that by the combustion of wood, peat, oil, \&c. there is added one third more, we produce a total of 2400 millions of kilogrammes daily.

In the case of the respiration of animals we can only form an approximate estimate. The population of the world is at present about 1500 millions; and it has been shown by experiment that each individual produces on an average about a kilogramme of $\mathrm{CO}_{2}$ per day of 24 hours. Thus the human race, in respiring, add to the air about 1500 millions of kilogrammes of carbon dioxide per day. Remembering the large

* The above calculations are made on the figures deduced from the results of the experimenters cited above. Recent investigations have, however, thrown some doubt on the correctness of these numbers, the general opinion being that 4 vols. in 10,000 is much too high. Thus, Fittbogen and Hasselbarth (Chem. Centr. 1875, p. 694) give 3.4 vols. in 10,000 as the average; Farsky (Chem. Centr. 1877, p. 198) found $3 \cdot 4$, while more recently Reiset (Comptes Rendus, lxxxviii. pp. 1007-1011) deduces 2942, Taking the mean of these numbers, we have

Weight of $\mathrm{CO}_{2}$ in air .... 1545 billions of kilogrammes nearly.

+ Mineral Statistics for Great Britain for 1881; and Smyth's 'Coal and Coal-Mining,' latest edition. 
amount of animal life existing on the globe, and also that many of the larger species produce a greater quantity in a given time, we may with a sufficiently near approach to accuracy say that from the lower animals the air receives twice as much daily as from man. Hence from the whole animal kingdom we derive about 4500 millions of kilogrammes.

The amount of dioxide which the atmosphere receives from decaying animal and vegetable substances is impossible to estimate. Most of it is produced in regions far away from the abode of man. That a considerable quantity is produced from this source, however, is evident when we consider the vast quantity of vegetable matter which year after year falls to the ground and undergoes decomposition. In fact, if the estimate of the amount of action exerted by plants given later on in this paper is a correct one, we must conclude that a much greater amount of dioxide is produced by this process than has been hitherto supposed. Although it is evidently impossible to give figures, yet, in order to arrive at a numerical estimate, we may assume that the same quantity is yielded as by man, viz. 1500 millions of kilogrammes daily.

The last source whence the air receives its supply of carbon is from volcanos and the fumaroles and rents in the ground in volcanic districts. The amount thus supplied is enormous, both active and extinct volcanos joining in increasing the quantity. Considering the area occupied by the volcanic districts, and the immense quantities of gas which are given off from the craters and fumaroles, we must readily come to the conclusion that from this source by far the greater part of the atmospheric carbon dioxide is derived. In fact Poggendorff bas calculated that at least ten times as much is derived from this source as from all others put together. The numbers given above for the amount yielded by other sources aro probably greater than similar numbers deduced by Poggendorff, since the amount of coal used and the population have both increased since his time. Instead, therefore, of taking ten times, if we take five we shall perhaps approach very near to the absolute amount given by Poggendorff. This will give us about 40,000 million kilogrammes daily given to the atmosphere from subterranean sources*.

Taking the whole of these results together, we have that from all sources there is daily added to the atmosphere the

* Supposing this $\mathrm{CO}_{2}$ produced according to the equation

$$
\mathrm{CaCO}_{3}=\mathrm{CaO}+\mathrm{CO}_{2} \text {, }
$$

we shall have daily decomposed about 90,000 million kilogrammes of limestone. 
enormous amount of at least 50,000 millions of kilogrammes of carbon dioxide. Dividing the absolute amount given above by this number, we find that the amount of carbon dioxide in the atmosphere would be double what it is at present in about one hundred years if there were no means of compensation. In arriving at this estimate no account has been taken of the amount of oxygen used up in producing the dioxide. This obviously affects the first three sources only; but by taking it into account we should reduce the time somewhat; but practically this correction is so slight that it can be neglected. Poggendorff made a similar calculation, and gave 386 years as the period which it would take to double the amount of the dioxide, supposing there were no compensating influences at work. The discrepancy in the two numbers is explained, first, by the absolute amount of $\mathrm{CO}_{2}$ in the air being much less according to my calculations than that previously supposed, and also by the circumstance that Poggendorff's estimate of the amount yielded by the combustion of carbonaceous substances was much less, owing to the defective data at his command.

\section{Compensating Influences.}

Having now arrived at an estimate of the amount of carbon dioxide daily added to the atmosphere, let us examine the causes which bring about its decomposition and removal from the air. The known causes which are at work producing this change may be considered under three heads, viz.:-

(1) Fixation of carbon by growing plants.

(2) Removal of dioxide by zoophytes.

(3) Absorption of dioxide by inorganic chemical actions.

The first cause here mentioned is one which is essential to almost all forms of vegetable growth. In estimating its magnitude we are met by the want of reliable experimental data, making it almost impossible to arrive at any definite conclusion. It is, however, the only one which restores the oxygen to the atmosphere, in the other two actions the dioxide being absorbed bodily without being decomposed. Also most, if not all, the decomposition effected by plants will occur during the spring and summer, the most active period of plant-growth. The second and third causes act continuously. Certain experiments have shown that a square metre of leaf will decompose in sunlight about a litre of $\mathrm{CO}_{2}$. Also Mr. Trelawny Saunders, some years ago, calculated for Sir Charles Lyell the area of the land-surface of the globe. The figures he gives are*:Total area of land . . . . . . 57,600,000 square miles. Area of Arctic and Antarctic land . 8,200,000

* Ansted's ' Physical Geography,' p. xxx viii. 
Thus the land-surface bearing vegetation capable of decomposing carbon dioxide amounts to $49,400,000$ square miles. A large portion of this land, however, is uncovered by vegetation : cities are built on it; barren mountains rise out of it; and large rivers run through it. Estimating the absolute area of leaf ( $i$. e. chlorophyll-bearing organs) borne by the plant-bearing land of the earth as 50 per cent. of the total area, we find that $24,700,000$ square miles of leaf are engaged in purifying the atmosphere. This is equal to about $63,973,000,000,000$ square metres, which gives the number of litres of $\mathrm{CO}_{2}$ decomposed per hour. But sunlight only lasts, on an average, about ten hours a day; consequently the total amount daily decomposed is equal to ten times this amount. Finally, allowing 25 per cent. for the diminution of the action which takes place in winter, we find that the enormous amount of 479,000 millions of kilolitres, or over 900,000 millions of kilogrammes of carbon dioxide are decomposed daily. This amount is much greater than that produced from all sources taken together. But it must be remembered that a large portion of the carbon thus withdrawn by plants during the spring and summer months is returned to the air again by the decomposition of the leaf in autumn. Although we have allowed for this above, yet if plant-action is anything like so powerful as these calculations show, that allowance will have to be considerably increased. Again, a reduction, and perhaps a considerable one, will have to be made on account of the respiration which has been proved to take place in some plants during the hours of darkness; but I am unable to find an account of any experiments upon this point. The magnitude of this action given by these calculations is astonishing. This paper was commenced under the idea that the action usually attributed to plants was greatly overestimated, and that their purifying effect was exaggerated. It will be seen that the vegetable life on the globe is sufficient of itself to keep up the purity of the air. The author wishes this statement to be received with cantion, because of the unsatisfactory nature of the fundamental experiment upon which the calculations are based, and also of our total want of knowledge of the amount of plant-respiration. This latter action may be much greater than is usually supposed.

The second great action going on in nature is effected by the interposition of animal life. It consists in the removal from sea-water of the carbon dioxide held by it in solution by certain low forms of animal life. The most important of these are Actinozoa and Foraminifera-the former being concerned in the building of coral recfs, and the latter in forming those 
immense masses of rock-material of which the chalk and nummulitic limestone maybe taken as examples. Certain other forms of animal life, such as Brachiopoda \&c., also add their influence to that of these lower forms; but their effects, however, are comparatively insignificant. The immense influence exerted by these minute creatures is evident when wo remember the vast masses of limestone entirely of organic origin occurring in geological formations of all ages. Millions of tons of limestone formed in this way occur in the solid crust of the earth; and every ton of limestone contains about nino hundredweight of dioxide. Nor is this action confined to the past. It is as active now, in all probability, as when engaged in building up those immense deposits of white chalk so abundant in some parts of Europe. Recent deep-sea soundings have revealed the fact that Foraminiferal life still flourishes in the depths of the ocean, while the coral-polypes are still building reefs in the warmer seas. On the other hand, we must not forget that Darwin has shown that these coralpolypes can only exist in water of a certain temperature, which is only'attained in the warmer seas, and at a certain depth below the surface of this water. Their influence, therefore, is limited and confined to a comparatively small area of the globe. Another circumstance which seems to have been overlooked by most writers upon the subject is, that this dioxide fixed in the solid state in this way is contained in the water, and not in the atmosphere. It is generally supposed that all of it has been derived from the air; but a very large portion must have been obtained from submarine volcanic eruptions, and never formed part of the atmosphere at all. Taking all things into consideration, this cause, although very powerful, seems rather to be one whose influence is only felt after the lapse of many years, and, for activity, cannot be equal to the first one.

The third action going on in nature effecting the purification of the air is a strictly inorganic one. Included under this head are such processes as the conversion of felspar into kaolin, the decomposition of such silicates as hornblende, pyroxene, \&c. The large deposits of kaolin and decomposed felspar which are met with in the earth sufficiently prove the magnitude of this action. Calculations were made many years ago by Ebelmen (see the Receuil des Trav. Scient. de M. Ebelmen, Paris, 1855), and have recently been recalculated and very clearly stated in an excellent paper by Dr. T. Sterry Hunt, F.R.S.* A glance at the numbers given in these memoirs will show the vast and important effect which these processes must have exerted.

* "Chemical and Geological Relations of the Atmosphere," American Journal of Science, May 1880.

Phil. Mag. S. 5. Vol. 14. No. 89. Nov. 1882. 
Thus, Dr. Hunt says" that a weight of carbonic dioxide equal to more than twenty-one times that of our present atmosphere would be absorbed in the production from orthoclase of a layer of kaolin extending over the earth's sturface with a thickness of 500 metres, an amount which evidently represents but a small proportion of the results of felspathic decay in the sedimentary strata of the globe." Evidently, then, here we have a cause which has removed, and is removing, a vast amount of carbon dioxide from the atmosphere. Any estimate of the rate of its action is obviously impossible. It must not be forgotten, however, that subaerial felspathic decay is a very slow process, and that therefore the large deposits of decomposed felspar found in the earth seem to point rather to a comparatively slow process acting through an immense number of years than to a rapid process such as that effected by plants.

\section{General Conclusions.}

It is of course evident that, if the compensating influences are just equal in amount and in rate of action to the producing ones, the amount of carbon dioxide in the air will remain constant. Unfortunately an insufficiency of reliable data prevents a definite answer being given to such a question. The foregoing considerations, however, seem to show that in all probability the causes at work removing atmospheric dioxide are more powerful than those producing it. As a consequence, the atmosphere is being robbed of this constituent, the greater part of which is becoming fixed in the solid earth as carbonate of lime. But this process has already gone on for so long a time, that there is already fixed in this way an immense quantity of $\mathrm{CO}_{2}$ equal to many hundreds of times the amount contained in the existing atmosphere. The question of the source of this large amount naturally arises; but the answer to be given must simply be an admission of our want of knowledge. The idea that it all at one time formed part of the atmosphere of the globe has been suggested by Brongniart; and Dr. Sterry Hunt considers (loc. cit.) that a universal atmosphere of the same quality as that of the earth exists, from which the carbon dioxide now fixed in the earth's crust has been derived.

There can be no doubt that, unless we accept the latter of these theories, there must at some antecedent period have been an atmosphere covering the globe much richer in this gas than the present one; but whether such an atmosphere would account for the luxuriant vegetation of the Coal Period is at present an open question. If Dr. Hunt's hypothesis be a correct one, it is interesting to remember that the carbon which we contain in our bodies may have existed at one time as a 
portion of the body of an inhabitant of the most distant member of the universe. But whichever way we consider the subject in the light of the facts which we have stated, it is full of unusual difficulty; and is singularly deroid of accurate experimental data.

XLIII. On the Dimensions of the Magnetio Pole in Electrostatic Measure.

To the Editors of the Philosophical Magazine and Journal. Geatclemen,

T HAVE had the honour of reading a letter upon the dimensions of the magnetic pole in electrostatic measuro which Dr. Lodge addresses to you this month. His suggestion seems to me to reconcile the views of Prof. Clausius and Mr. J. J. Thomson on this subject. A model of the magnetic system must be made in a substance of the same magnetic permeability as the medium that is to surround the currentsystem, and must be substituted in the place of the magnets, before any comparison can be effected. The two systems, current-and magnetic, will then be always equivalent if once equivalent.

Dr. Lodge treats this as a suggestion; but $I$ think it is almost susceptible of demonstration. According to Weber's law, a current flowing in a closed circuit can be replaced by a simple magnetic shell of which the edge coincides with the circuit. The shell may be as thin as we please; but its strength must have a definite value. This law we only know to be true for air. Consider any equipotential surface of the positive magnetism on one fare of the shell, at a distance from it infinitely smaller than the thickness of the shell. It passes through the substance of the shell, issuing at the edges, and covers the positive face. Similarly such an equipotential surface of the negative magnetism on the other face passes through the substance without cutting the former surface, and covers the negative face.

If on each of these surfaces we spread a surface-magnetism of which the density is the quotient of the magnetic force by $4 \pi$, then for all points outside the pair of surfaces and the shell we may replace the latter, and thercfore its equivalent currentsystem, by the magnetic couts upon the equipotential surfaces.

Now consider any diaphragm, $\mathbb{S}$, completely enclosing these surfaces and the shell. If instead of ail we substitute a medium of magnetic permeability $\mu$ throughout space outside $\mathrm{S}$, a surface-density $\sigma$ is developed upon $\mathrm{S}$. But the equipotential surfaces and the conts of magnetism thereon are not affected by this development; for they relate only to the en$2 \mathrm{D} 2$ 